\title{
Que haja luz! A construção do espaço a partir da luz - a luz como meio da encenação teatral ${ }^{1}$
}

There may be light! The emergence of space through lighting - Light as a means of theatrical performance

Erika Fischer-Lichte ${ }^{2}$ Tradução: Stephan Arnulf Baumgärtel ${ }^{3}$ 


\section{Resumo}

O texto de Erika Fischer-Lichte, em tradução de Stephan Arnulf Baumgärtel, discute os procedimentos de iluminação cênica para as relações palco-platéia numa perspectiva histórica.

\section{Abstract}

This text by Erika Fischer-Lichte, translated by Stephan Arnulf Baumgärtel, discusses under a historical perspective some principles of stage lighting that were used to model the relations between stage and audience.

ISSN: 1414.5731

E-ISSN: 2358.6958 
Ao longo do século XVII, as apresentações teatrais foram paulatinamente transferidas do dia para a noite e do ar livre para espaços fechados. Para que isso pudesse acontecer, teve que ser introduzida a iluminação artificial. Lâmpadas a óleo, velas, tochas, todas elas deveriam, com sua luz, assegurar que os espectadores pudessem ver bem as atividades realizadas no palco e no espaço da plateia.

Em pouco tempo, o novo sistema de iluminação foi aperfeiçoado a tal ponto que se tornou um meio teatral autônomo - ao lado da arte da atuação, do figurino, da decoração e da música. A partir desse momento, o uso da luz definiu os espaços de maneira específica e lhes abriu novas possibilidades de criar impactos e significados.

A iluminação forte e equilibrada do palco e da plateia durante o século XVII configura ambos como espaços de representação. No espaço da plateia, entretanto, a iluminação oportunizou não apenas perceber a ordem social específica, tal como foi representada pela organização fixa dos lugares dos espectadores e por seu comportamento, mas também a interação social dos espectadores conforme as regras dessa ordem. O espaço dessa plateia tinha que ser pensado enquanto espaço expositivo, no qual os membros da corte se expunham e mostravam sua posição social. Na França, isso chegou a tal ponto que os espectadores se sentavam em poltronas sobre o palco, ao passo que mal restava um espaço para que os atores realizassem suas ações.

O uso da iluminação no palco o definia especificamente como um espaço significativo. Com a ajuda de dispositivos simples - como placas de metal, bolas de vidro cheias de água, espelhos ou a lanterna mágica - era possível criar efeitos de iluminação espantosos que induziram nos espectadores medo, horror, fascinação ou admiração contemplativa. Sobretudo, dois tipos de efeitos se sobressaíram: os efeitos ofuscantes do fogo e os efeitos suaves da luz.

Os efeitos de fogo foram usados para representar erupções vulcânicas e incêndios, para mostrar queda de raios e fazer com que cometas corressem pelo céu ou o inferno cuspisse chamas fulgurantes. Deveriam induzir horror, medo e terror, e apontar as catástrofes iminentes por meio das quais se revelam os atos do diabo neste mundo. Esses efeitos deveriam ser relacionados com a esfera do mau e do satânico.

Em contraposição, os suaves efeitos de iluminação: as auréolas santas, as nuvens reluzentes das quais desceram santos ou anjos à terra e, sobretudo, as apoteoses finais. Neles apareceram, em esplendor brilhante, as insígnias do reino, a assinatura do soberano, a hóstia ou a cruz. Esses efeitos luminosos faziam referência às esferas do divino. Tinham que causar admiração e contemplação, e funcionavam como signos da manifestação do divino no mundo.

A luz, como meio de criação teatral, podia, de forma privilegiada, fazer referência ao satânico tanto quanto ao divino. Assim, a luta de forças transcendentais pela alma do indivíduo ou pelo destino do mundo podia ser apresentada com a ajuda de signos que eram, para a época, representações perfeitas dessas forças: o fogo enquanto representação do satânico e a luz enquanto representação do divino. 


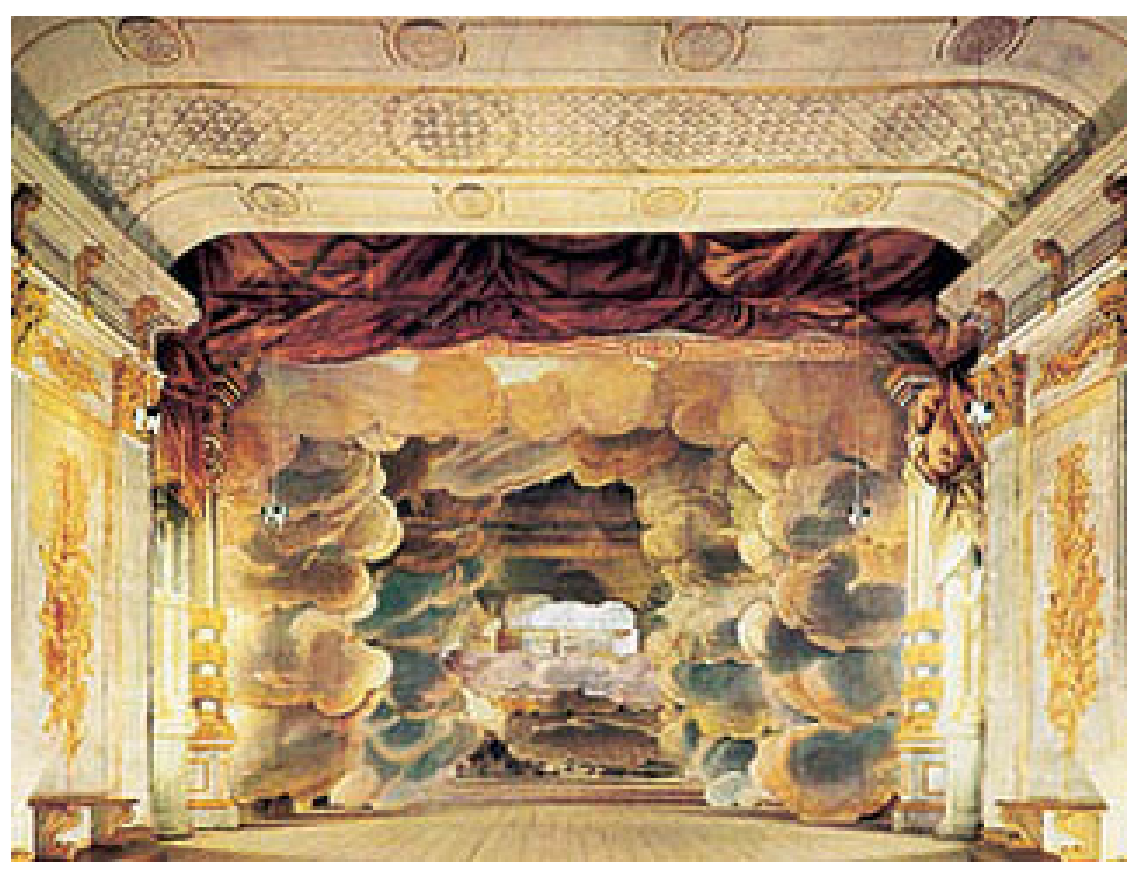

Drottningholm, Bühnenbild von J.L. Deprez

Foto: Institut für Theaterwissenschaft

Quando terminava a apresentação, durante a apoteose final, o nome do soberano luzia em letras brilhantes na escuridão do palco, ou a hóstia aparecia em uma coroa de raios de luz para iluminar o mundo do palco com sua luz. A delimitação do espaço parecia diluir-se na expansão infinita da luz. Esse processo não deve ser compreendido apenas como um signo que apontaria para a fama e a grandeza do soberano ou a graça divina de um modo geral. A sublimação do mundo do palco na luz da apoteose predizia, antes de mais nada, o resultado final daquela batalha: o mundo inteiro a ser igualmente acolhido no reluzir da graça divina. De modo equivalente, podemos compreender a apoteose final como alegoria da ressureição e da vida eterna que permitia ao espectador experimentá-las, pelo menos esteticamente.

Enquanto o espaço da plateia era iluminado, ele continuava sendo um espaço social. Embora, na segunda parte do século XVIII, não tivesse mais a função de representar a ordem social, era um espaço no qual o cidadão, como ser humano sensível, podia expor suas lágrimas e outras expressões afetivas. $O$ "contágio afetivo" podia dar certo, sobretudo porque o espectador em prantos também via os outros espectadores chorando. Apenas porque a comoção comum podia ser vista por cada espectador, ela podia criar impactos intensificadores e unificadores.

Artigos críticos publicados nas revistas de teatro até a segunda metade do século XIX mostram que o espaço da plateia funcionava também, em outro sentido, como um espaço gregário: as pessoas chegavam e saiam, comiam e bebiam, bisbilhotavam entre as fileiras, tentavam descobrir com um binóculo o que acontecia em outros camarotes e discutiam esses assuntos mais vivaz e desavergonhadamente do que os acontecimentos na cena.

Nos anos vinte do século XIX, introduziu-se a iluminação a gás que permitiu escurecer a plateia. Foi Charles Kean, na Inglaterra, quem começou nos anos quarenta 
a realizar os primeiros experimentos nesse sentido. $O$ primeiro a escurecer o espaço da plateia de modo consequente durante a apresentação foi Richard Wagner. O vai-evem social - sobretudo do público de óperas nas noites de estreia - lhe causava tanta repulsa que, em 1876, tentou acabar com isso de uma vez por todas durante o primeiro Festival de Ópera, em Bayreuth.

O escurecimento fez com que o espaço da plateia deixasse de ser um espaço gregário. Posto na escuridão, o espectador podia perceber as reações dos outros espectadores apenas quando elas se articulavam sonoramente. Ao invés de poder criar uma relação com os acontecimentos cênicos tanto quanto com os outros espectadores, ele tinha que direcionar sua atenção exclusivamente para o palco. Wagner denominou essa nova atitude do espectador, exigida por ele, "um intuir crepuscular; um sonhar algo nunca vivenciado como se fosse verdade". Para o espectador sentado no escuro, o palco - que recebeu toda a iluminação - se tornou, nesse sentido, o seu "espaço interior", ou seja, o espaço no qual ele viu seus sonhos postos em ação, fossem desejos ou pesadelos. O palco se transformou numa "imagem onírica", como formularia Hugo von Hofmannsthal pouco mais de trinta anos depois.

Para que o espectador pudesse de fato percebe-lo como seu "espaço interior", sua imagem onírica, o palco tinha que transformar-se em um tipo de espaço fundamentalmente diferente. O palco deveria tornar-se um espaço móvel, algo que não podia ser criado com a ajuda da iluminação a gás. Para isso, foi necessária a invenção da luz elétrica.

O cenógrafo suíço Adolphe Appia exigia em seu texto "A música e a encenação", publicado em 1899, um uso completamente novo da luz. Não por acaso ele desenvolveu essa teoria em relação ao drama musical de Richard Wagner. Pois ambos almejaram, por meio da iluminação, criar aqueles espaços móveis que possibilitariam, antes do mais nada, "um intuir crepuscular; um sonhar de algo nunca vivenciado como se fosse verdade". Appia baniu os bastidores do palco, estruturou o chão do palco por meio de diferentes escadas, degraus e pedestais que permitiam ao ator-performer posições e movimentos mais variados no espaço e, desse modo, pareciam transformar o espaço em movimento rítmico. Mas, como "falta a expressividade" se "falta a luz", Appia propôs usar a iluminação de tal maneira que o jogo constantemente mutante entre luz e sombra gerasse o espaço como um espaço móvel e em movimento. "O estado líquido da luz, de uma condução incomparável, também torna líquido o espaço." Appia pensou que, dessa maneira, a luz poderia criar o espaço como um espaço em constante transformação e dotado de uma mobilidade interna.

Com a técnica de iluminação disponível na virada do século XIX para o século XX, as visões de Appia puderam ser realizadas apenas de modo rudimentar. O que Appia talvez tivesse em mente foi realizado por Robert Wilson através do uso de uma iluminação computadorizada.

Se durante 120 minutos, mais do que 300 posições de luz são apresentadas, de fato surge um espaço constantemente em transformação, movimentado e móvel, sem fronteiras claras, que nos dá a impressão de imagens oníricas trêmulas que passam à nossa frente. São esses tipos de espaço que oportunizam ao espectador "um intuir crepuscular, um sonhar, como se fosse verdade, algo nunca vivenciado" e, com isso, experiências bastante especiais. Não foi apenas após a invenção da iluminação com- 
putarizada, mas já desde a introdução da iluminação artificial no século XVII, que se usou a luz no teatro para criar experiências específicas para o espectador, em relação ao espaço.

Quando um cometa com calda fulgurante corria pelo céu cênico, criava-se uma atmosfera sinistra de medo e terror. Quando as nuvens resplandeciam em uma luz suave e, com um anjo, desciam vagorosamente à terra escura e a iluminavam com seu brilho, criava-se uma atmosfera serena e impregnada da promessa de felicidade.

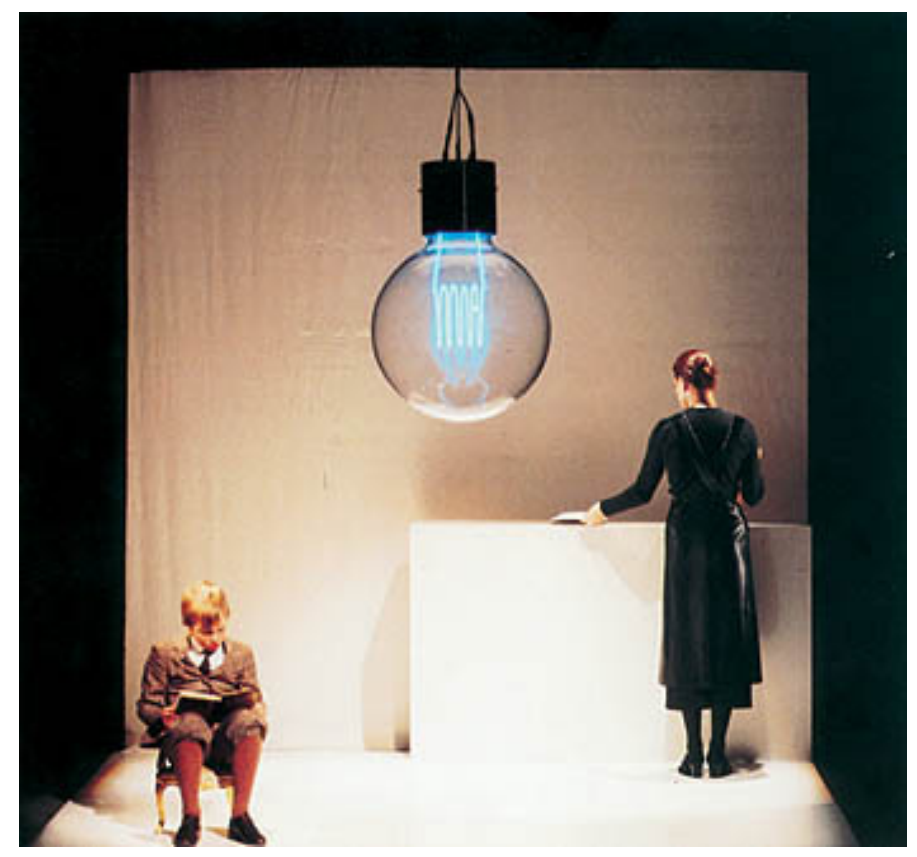

Light Bulb in der Aufführung von Robert Wilsons Death Destruction and Detroit I, Schaubühne, Berlin, 1979 Foto: Institut für Theaterwissenschaften

De modo algum se pode dizer que foi somente a partir do teatro romântico dos anos 30 e 40 do século XIX (que, com o apoio da iluminação a gás, sabia produzir as atmosferas "românticas" mais diversas), ou com Max Reinhardt (esse mestre na criação de atmosferas no início do século XX), que se começou a usar a luz para criar atmosferas. Desde que existe a iluminação artificial, usa-se a luz para instaurar atmosferas. Não é apenas a luz que contribui para a criação de uma atmosfera, mas, via de regra, os ruídos simultaneamente audíveis (como o estrondo que acompanha o cometa) ou a música (como no caso das nuvens que descem), assim como também certos objetos, pintados ou móveis, perceptíveis no espaço cênico. Entretanto, a luz na qual esses objetos são banhados - seja como luz calorosa, amigável, fosca ou fria - desempenha um papel especial para caracterizar a atmosfera. É a luz que define se a atmosfera nos toca como sinistra, opressiva, perturbadora, melancólica, triste, depressiva, leve, pacífica, tranquilizante ou feliz.

Ora, atmosferas não devem ser compreendidas nem como algo que existe objetivamente - como nos mostrou Gernot Böhme em seu livro Atmosphären (1995), como se fossem características possuídas pelas coisas das quais parecem emanar -, nem como algo subjetivo, ou seja, como estado psíquico do sujeito perceptivo que este 
projeta no espaço com seus objetos. Mesmo que, por um lado, as atmosferas pertençam às coisas, já que as primeiras aparecem por meio das características das últimas, atmosferas são, por outro lado, subjetivas, no sentido de que os seres humanos as projetam em sua presença corpórea. Em outras palavras, a atmosfera precisa ser pensada como algo que se "derrama" espacialmente entre o objeto e o sujeito. De fato, é "o estado líquido da luz, de condução incomparável" da qual falou Appia, que confere às atmosferas esse modo existencial específico. Ele assegura que elas, por assim dizer, acontecem no espaço entre palco e plateia, e define o espaço da atmosfera especificamente como um intervalo móvel. Nesse contexto, a atmosfera não pretende referenciar algo "romântico". Mesmo que o autor Bertold Brecht decidisse usar a luz apenas em sua função prática, ou seja, tornar o palco visível, e pusesse grande ênfase no fato de que os espectadores pudessem ver os refletores, ele nada mais fez do que criar uma atmosfera - a atmosfera de trabalho - que o espectador sentiu corporalmente, e que influenciou decisivamente sua percepção e recepção dos acontecimentos cênicos.

Desde que a invenção da iluminação elétrica ampliou consideravelmente as possibilidades técnicas de uso da luz no teatro, os artistas do teatro experimentaram todas essas possibilidades durante o século XX. lluminaram ou escureceram o espaço da plateia de todas as formas, usaram a luz no palco em funções as mais diversas e, dessa maneira, criaram permanentemente novos espaços. Qual tipo de espaço a luz cênica criava em diferentes montagens - muitas vezes do mesmo diretor como, por exemplo, Max Reinhard, que praticamente usou de modo diferente a luz em cada encenação -, isso tem que ser analisado caso a caso. Mas, como foi mostrado, para tal tarefa pode-se pressupor que é a luz que gera o espaço e o define em sua especificidade.

Recebido em: 25/11/2014

Aprovado em: 28/11/2014 